\title{
Virtual Laboratory Construction of College Computer Hardware Course Group
}

\author{
Wang Haiyan*
}

Department of Information Engineering, Binzhou University, Binzhou. Shandong, 256600, China

\begin{abstract}
Purpose: Study construction methods of virtual laboratory for college computer hardware course group and discuss feasibility and practicability of virtual lab; Method: Introduce principle and technologies of the virtual lab, analyze construction method of the virtual test, establish the online college open laboratory platform based on college experimental platform, and design and simulate classical microcontroller circuit-LCD electronic clock with virtual laboratory for microcontroller principle as one example; Results: simulation results indicate that the virtual laboratory for microcontroller principle can effectively design the hardware circuit and software programming and simulate based on the software and hardware. The simulation results are ideal; Conclusion: the virtual laboratory for college computer hardware course group is practicable to some extent, can improve the practice capability of students, and meet the experimental requirements of modern colleges.
\end{abstract}

Keywords: Hardware course group, virtual lab, experimental platform, microcontroller, electronic clock.

\section{INTRODUCTION}

With further deepening of the reform and opening in China and continuous improvement of sciences and technologies, high education has developed quickly. Since reform and opening, the colleges effectively combine with development of local economy and adjustment and control of the national policies, strengthen use of information sciences and technologies, computer science technologies and network sciences and technologies, improve the investment mode of traditional discipline education, optimize proportion of traditional specialty disciplines, and improve teaching quality, so colleges train talents for local economies and contribute much to quick, healthy and sustainable development of economy and society and reform and development of high education [1, 2] in China. In Jan, 2007, the Ministry of Education issued "Recommendation for implementation of college undergraduate teaching quality and teaching reform engineering" and planned to implement "college undergraduate teaching quality and teaching reform engineering (called as 'quality engineering')". With specialty structure adjustment, construction of course teaching materials, practice teaching reform and teaching team construction, the Ministry of Education aims to further deepen teaching reform of colleges, improve capability and level of talent cultivation, and better meet the demand of economy and society development for high-quality talents [3], otherwise, the high education quality should be further improved to adapt the demand of economy and society development. Specialty setup and structure is not reasonable, whole quality of teaching team is

*Address correspondence to these authors at the Department of Information Engineering, Binzhou University, Binzhou. Shandong, 256600, China; Tel: +8618935963567; E-mail: wanghaiyanhy57@163.com imminent to improve, and talent cultivation pattern, teaching contents and methods should be further transformed in many colleges. The society pays more and more attention to practice capabilities of students. Therefore, it is imminent to reform laboratory construction and experimental teaching means [4]. Now many colleges are conscious of important of the laboratory teaching and plan the laboratory construction in the agenda. However, it is difficult to make investment to the experiment teaching meet actual demand due to fund and site of laboratory construction. Now students cannot practice by themselves and can only practice in a traditional "face-toface" manner in many colleges. This teaching mode can not meet the requirements of expected training plan, so the concept of the virtual laboratory is proposed under this background [5].

The virtual laboratory (VL) is an open networking virtual experiment teaching system based on Web technology and VR technology, which digitalizes and virtualizes different teaching laboratories. The VL consists of the virtual experimental table, virtual apparatus warehouse and open laboratory management system [6,7]. VL provides a brand-new teaching environment for different virtual experimental courses. The virtual experimental table is like a true experimental table via which students can configure, connection, adjust and use the experimental instrument and equipment by themselves [8]. Teachers can freely establish any reasonable typical experiment or experiment case by using the apparatus in the virtual apparatus warehouse, which is the important feature different from common experiment teaching courseware [9]. In other word, the VL is a computer assisted teaching software, which can simulate experiments of actual objects by using the VR technology, establish a virtual experiment teaching environment on computers by using the multimedia information technology, and enable students to 


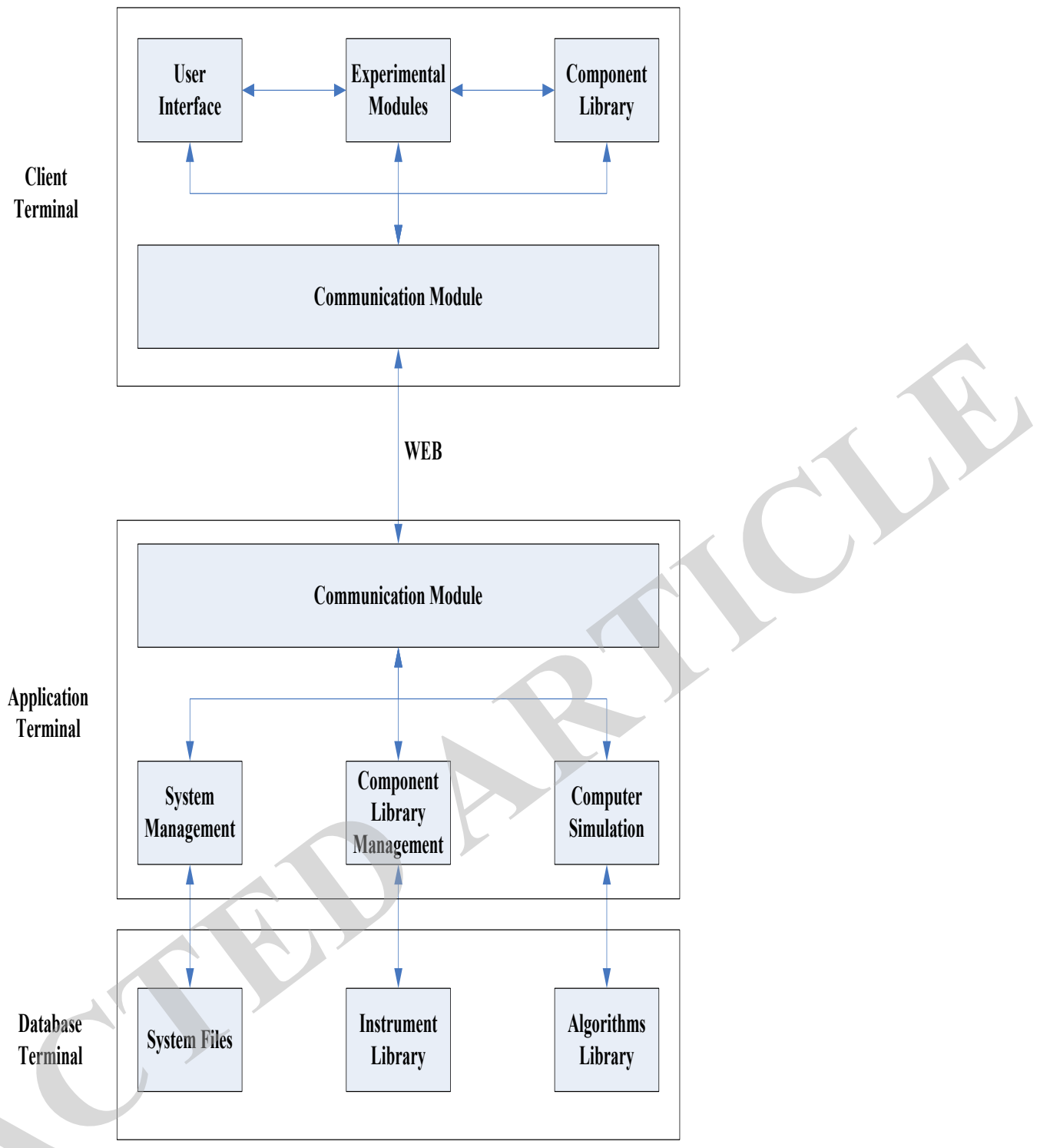

Fig. (1). Structure of VL platform.

complete experiments on the human-machine interaction interface approximating to true interface via Internet. Students can operate on the virtual experimental table and independently design experiments at VL, which can facilitate cultivation of operation capability, analysis and diagnosis capability, design capability and innovation consciousness. Students can easily get related knowledge, scientific guidance and acute feedback at VL [10]. VL represents development direction of the laboratory construction in future. This paper aims to study VL construction of the college computer hardware course group, analyze actual application value of VL with VL for microcontroller principle as one example, and provide research basis for modern college experiment teaching.

\section{FEASIBILITY ANALYSIS FOR VL CON- STRUCTION}

The VL is an experimental system, which is generated by using VR technology and is suitable for virtual experiments, including corresponding laboratory environment, related experimental instrument and equipment, experimental objects and experimental information resources. Students can observe one experiment object from different views in a simulated 3D experimental scenario on a computer in the VL and can select or drag via the mouse to complete interaction with the virtual experimental objects. The virtual teaching laboratory system is designed and studied in order to provide a virtual experimental environment to users under which users can get different components, and connect, copy, move and delete them. The structure of a VL platform is shown as the Fig. (1).

1) Powerful simulation software: in fact, a VL applies the digital simulation technology into the experiment teaching. The true foreground of the virtual experiment teaching system is the multimedia or virtualized environment. The background is the real-time simulation process. Now the frequent simulation software includes EASY-T, VT-LINK3.3, SPW, Cadance, Mentor, MatLab, Protel2004, LabView, OpenGL and MultiGen. When a virtual experiment is constructed, a 


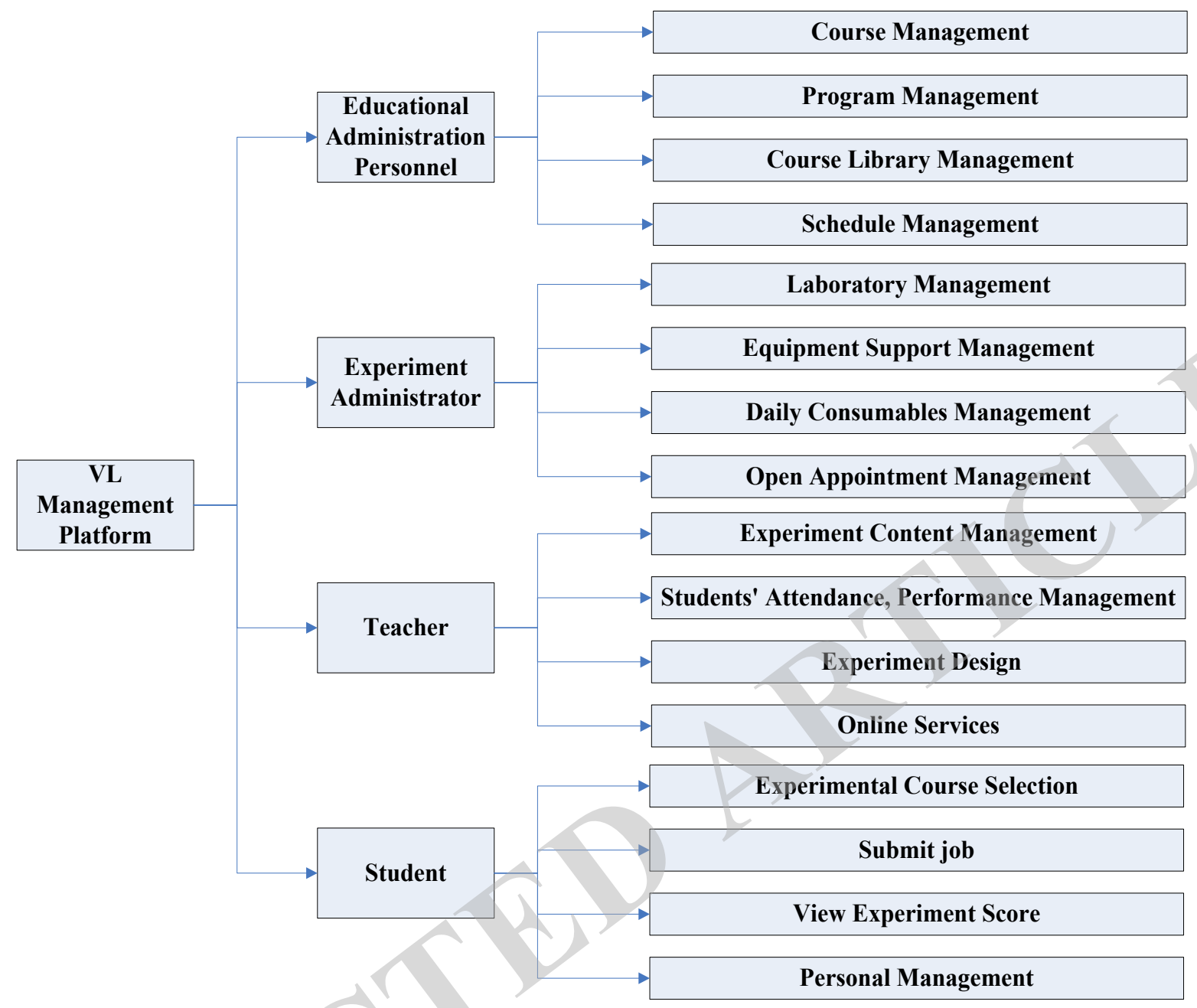

Fig. (2). Platform function structure framework.

proper development tool should be selected according to specific requirements. How to combine the computer simulation technology with the virtualizedinstrument or multimedia environment seamlessly is the key and core technology for VL construction.

2) Rich technology support: In recent years, the virtual technology has quickly developed. Now the VL is developed by using some tools at home and abroad, including JAVA+VRML, ActiveX control, QuickTime VR and FLASH. FLASH is a graphic system based on vector and features small scale, powerful functions, random zoom, better compatibility and embedded ActionScript function. FlashActionScript is the best platform of development of the network teaching VL.

3) Diversified function module: Now the domestic and foreign college VL systems are divided into database, simulation experiment system and network services by function modules. The database can provide related data services, maintain data information and user privileges, and support simulation experiments in the VL system. The simulation experiments enable users to construct the experimental models and design virtual instrument and equipment, experimental lines or circuits, experimental parts or component library, and experiment effect criterion by using the computer simulation technology. The network services enable users to register personal information via a network and log into the virtual experiment system after validation. After logging into the system, students can independently select experiments to perform and get related guidance according to the actual requirements.

\section{ESTABLISHMENT OF OPEN LABORATORY INTEGRATED MANAGEMENT PLATFORM}

The open experiment integrated management platform orients to experiments of students in colleges, focuses on VR experiments, sticks to the rule of normalization, management informatization and standardization, and features transparency, resource sharing, intelligence, interoperability, customercustomized manageability and scalability. Based on the open experiment platform in colleges, this paper optimizes and adjusts it, expands its functions based on old technologies, and develops out a modern college open experiment platform. The functions and structure framework of this platform is shown as the Fig. (2). 
The above figure indicates that we use the website VL management platform in design of the college open experiment platform, which is divided into teaching and management personnel module, experiment administrator module, teacher module and student module by user's decision. The teaching administrator can manage the course library, student training plan, course opening and choice and course table. The experiment administrator can manage laboratories, routine laboratory consumables, fixed assets and open subscription. The teacher module mainly realizes experiment content scheduling, attendance management, online service, assessment and summary. The student module can realize experiment task submission, experiment scheduling, experiment design and credit query.

\section{CONSTRUCTION OF VL FOR MICROCON- TROLLER PRINCIPLE}

The microcontroller is an integrated circuit chip, which integrates CPU with data processing capability, RAM, ROM, multiple I/O and interruption system, timer/counter (maybe including display driving circuit, pulse width adjustment circuit, analog multi-channel converter and $\mathrm{A} / \mathrm{D}$ converter) into one silicon chip by using a ultra-large integrated circuit in order to compose a small and perfect micro computer system. The microcontroller is a highly practicable application electronics technology, so this paper selects the microcontroller principle as the object to study and establishes the VL for microcontroller principle for related learners to learn. The VL platform provides hardware circuit design, software program design, and software and hardware combined simulation function for microcontroller application and development. For simplicity, this paper selects the course exercise question "Make an electronic clock" of the course "Microcontroller principle" as one example to design and simulate it via VL.

\subsection{Design of Hardware Circuit}

Before the hardware circuit is designed, the author introduces a hardware circuit design tool-Proteus, which is the EDA tool software provided by England Laboratory Center Electronics (the general agent of this software is Guangzhou Fengbiao Electronics Technology Co., Ltd.). Proteus not only provides the simulation functions of other EDA tool software, but also simulates the microcontroller and peripheral parts. Now Proteus is a better tool to simulate the microcontroller and peripheral parts, which can realize principle layout, code debugging and collaborative simulation of microcontroller and peripheral circuit, switch to PCB design via one push key, and truly realize the complete design from the concept to products. Now Proteus is the unique design platform in the world, which integrates circuit simulation software, PCB design software and virtual model simulation software and supports processor models such as 8051, HC11, PIC10/12/16/18/24/30/DsPIC33, AVR, ARM, 8086 and MSP430. In 2010, Cortex and DSP processors are added and other processor models will be further added.
The following part shows how to make a LCD intelligent electronic clock with AT89C51 microcontroller as the core.

Design requirement: (1) count time: second, minute, hour, day, week, month and year; (2) automated determination of leap year; (3) five-channel timing output and random on/off (maximum 16 channel); (4) alternate display of time, month and day; (5) Turn on/off screen at any scheduled time; (6) Time counting precision: error $\leq 1 \mathrm{~s} /$ month (micro adjustment setting); (7) The keyboard is queried by dynamic scanning. All query and setup functions can be completed via the function key K1 and K2. The Proteus simulation circuit is shown as the Fig. (3).

\subsection{Design of Software Program}

Keil C51 is C language software development system for 51 series compatible microcontroller provided by America Keil Software. Compared to the assembly language, C language has significant strengths in function, structure, readability and maintainability and is easy to learn and operate. Keil provides a complete development scheme, including C compiler, macro assembly, connector, library management and powerful simulation debugger, which are combined via one integrated development environment.

The main programs of this paper are described as follows:

$$
\text { \#include }<\text { reg52.h }>
$$

\#include $<$ intrins.h $>$

$\cdots$ byte

void write_ds1302_byte(uchardat) / DS1302 write single-

$$
\{\ldots . .\}
$$

void write_ds1302(uchar dat1,uchar dat2) /DS1302 write single-byte

$$
\begin{aligned}
& \{\ldots \ldots\} \\
& \text { uchar read_ds1302(uchar add) /DS1302 read } \\
& \{\ldots \ldots\} \\
& \ldots \ldots . . \\
& \text { void display }() \quad \text { /Display } \\
& \{\ldots \ldots \\
& \text { void main }() \\
& \{\ldots \ldots\}
\end{aligned}
$$

\subsection{Circulation Simulation}

Open a microcontroller property window of the parts, add the above compiled target code files at "Program File" menu, and input the crystal frequency $11.0592 \mathrm{MHz}$ at "Clock Frequency" field. The simulation results are shown as the Fig. (4). 


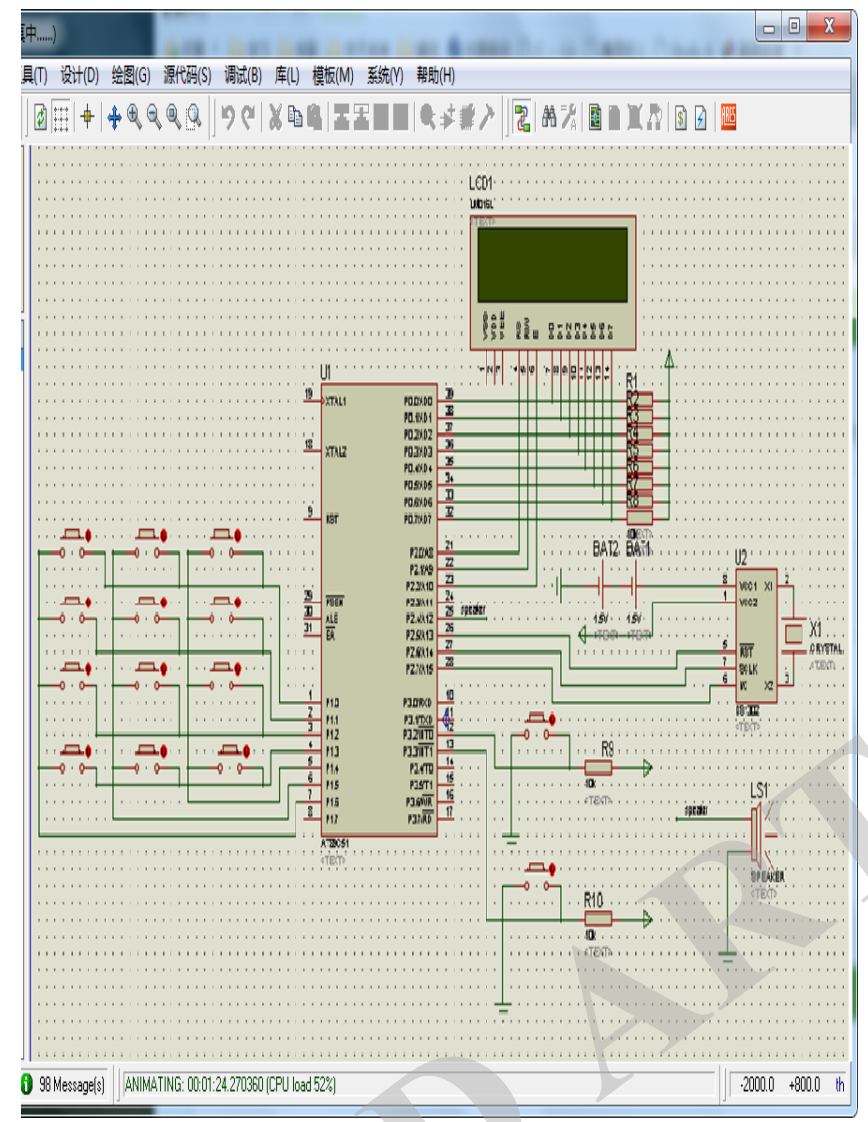

Fig. (3). Simulation circuit diagram.

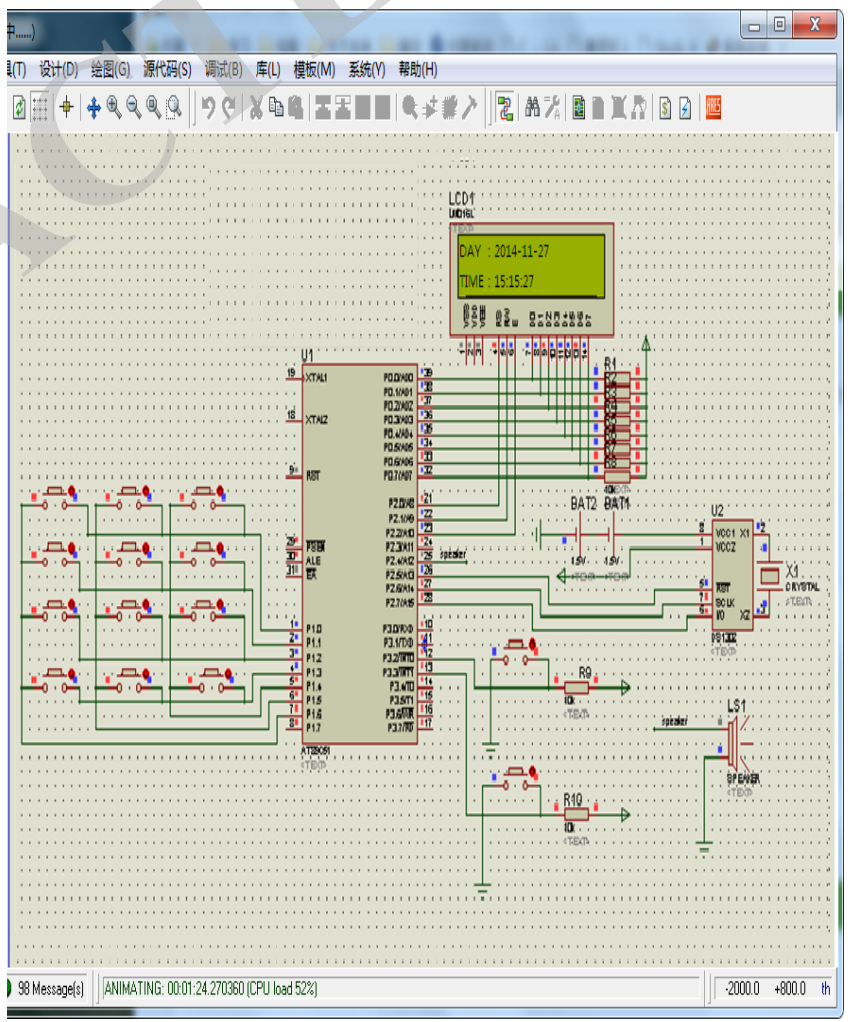

Fig. (4). Circuit simulation diagram. 


\section{CONCLUSION}

The VL consists of servers and clients based on the network. A client can use experiment materials stored on servers to enable students to practice experiments. Besides the virtual laboratory for microcontroller principle in this paper, some frequent virtual laboratories such as "animal laboratory", "chemistry laboratory" and "physics laboratory" can be constructed. Although the virtual laboratory can not replace traditional laboratories in actual applications, it has the advantages not provided by traditional laboratories, e.g. solve problems due to actual economy factors and space factors. The traditional laboratories should be combined with the virtual laboratories to meet teaching requirements in actual teaching and learning. To study the construction of VL for the college computer hardware course group, this paper mainly studies construction of VL for microcontroller principle and describes theory knowledge for VL construction in detail. The established VL for microcontroller principle is used to simulate DS1302 experiment. Proteusis used to design circuits based on typical microcontroller principle circuit diagram. The $\mathrm{C}$ language is used to design programs. The simulation results indicate that the established VL for microcontroller principle can be used to design the circuit diagrams. Proteus can call keil-1.hex files for simulation. The simulation results are ideal and are practical to some extent. The VL can improve the practice capability of students and meet the experiment requirements in modern colleges.

\section{REFERENCES}

[1] H. Cao, Research and Design of Virtual Laboratory for Computer Composition Principle, Shandong University of Technology: Shandong Zibo, 2008.

[2] C. Li, Z. Lu, and Y. Gong, "Construction of virtual laborary for college computer hardware course group," Journal of Yulin Normal University (Natural Science Ed.), vol. 35, no. 2, pp.126-129, 2014.

[3] M. Can, Research and Development of Computer Hardware Virtual Experiment Platform, Central South University: Changsha, 2005.

[4] Y. Yao, G. Su, and L. Feng, "Construction and exploration of network virtual laboratory for engineering specialty," Experiment Research and Exploration, no. 32, pp. 213-215, 2013.

[5] Y. Rong, W. Wang, J. Yuan, and Y. Sun "Construction of virtual laboratory", Journal of Power System and Automation, no. 24, pp. 86-90, 2012.

[6] M. Limniou, N. Papadopoulos, and C. Whitehead, "Integration of simulation into pre-laboratory chemical course: computer cluster versus web CT," Computers and Education, pp. 45-52, 2009.

[7] B. Barros, T. Read, and M.F. Verdejo, "Virtual collaborative experimentation: an approach combining remote and local labs," IEEE Transactions on Education, vol. 51, no. 2, pp. 242-250, 2008.

[8] E. Jiang, X. Wang, S. Li, and Y. Yang, "Construction of virtual laboratory for computer network course," Experiment Science, no. 15 , pp. 132-135, 2012.

[9] Y. Wang, G. Li, Y. Ying, and L. Jia, "Construct network virtual laboratory and deepen experiment teaching reform," Experimental Technology and Management, no. 27, pp. 86-87, 2010.

[10] H. Diao, and M. Yu, "Simulation implementation of computer composition principle experiment instrument based on virtual instrument," Journal of North East Forestry University, vol. 33, no. 2, pp. 98-99, 2005.

\section{CONFLICT OF INTEREST}

The authors confirm that this article content has no conflictsof interest.

Received on: May 26, 2015

Revised on: July 14, 2015

Accepted on: August 10, 2015

(C) Wang Haiyan; Licensee Bentham Open.

This is an open access article licensed under the terms of the (https://creativecommons.org/licenses/by/4.0/legalcode), which permits unrestricted, non-commercial use, distribution and reproduction in any medium, provided the work is properly cited. 